\title{
An Optimization Framework for Workplace Charging Strategies
}

\author{
Yongxi Huang $^{\text {a** }}$ and Yan Zhou ${ }^{\mathrm{b}}$
}

a. Assistant Professor, Glenn Department of Civil Engineering, Clemson University, Clemson, SC 29634, yxhuang@clemson.edu

b. Transportation System Analyst, Argonne National Laboratory, 9700 S Cass Ave, Bldg 362 Lemont, IL 60439, yzhou@anl.gov

* Corresponding author, Tel: 1-864-656-3661, Fax: 1-864-656-2670

1

(C) 2015. This manuscript version is made available under the Elsevier user license http:/www.elsevier.com/open-access/userlicense/1.0/ 


\begin{abstract}
The workplace charging (WPC) has been recently recognized as the most important secondary charging point next to residential charging for plug-in electric vehicles (PEVs). The current WPC practice is spontaneous and grants every PEV a designated charger, which may not be practical or economic when there are a large number of PEVs present at workplace. This study is the first research undertaken that develops an optimization framework for WPC strategies to satisfy all charging demand while explicitly addressing different eligible levels of charging technology and employees' demographic distributions. The optimization model is to minimize the lifetime cost of equipment, installations, and operations, and is formulated as an integer program. We demonstrate the applicability of the model using numerical examples based on national average data. The results indicate that the proposed optimization model can reduce the total cost of running a WPC system by up to $70 \%$ compared to the current practice. The WPC strategies are sensitive to the time windows and installation costs, and dominated by the PEV population size. The WPC has also been identified as an alternative sustainable transportation program to the public transit subsidy programs for both economic and environmental advantages.
\end{abstract}

Keywords: Workplace charging, optimization, resource allocation 


\section{INTRODUCTION}

To further expedite the adoption of plug-in electric vehicles (PEVs), the U.S. Department of Energy (DOE) launched the program "Workplace Charging (WPC) Challenge" in 2013 (DOE, 2014), "with a goal of achieving a tenfold increase in the number of U.S. employers offering workplace charging in the next five years". The WPC has been recently recognized as the most important secondary charging point next to home charging. The benefits of the WPC involve not only employees but also employers, communities, and PEV marketplace. For employees, the WPC will likely double the commute range of using PEVs, enable employees who live distant away from workplace (e.g., 40 miles one-way) to adopt PEVs as a viable alternative commute means (Pearre et al., 2011), and provide PEV users who live in multi-dwelling building with daytime charging opportunities. In some states, public policies further incentivize the use of PEVs, such as granting high occupancy vehicle lane access (e.g., California), which encourage employees living in congested urban areas to use PEVs for commute. For employers, the WPC can be a cost-effective alternative employee benefit program to the traditional public transit or carpool incentive programs while attracting and retaining a talented workforce. The WPC will also help leverage up the corporate's "Green Image", which can be part of sustainability programs. In addition, the WPC also provides companies with opportunities to convert its own fleet to PEVs and save operation costs by charging the fleet overnight.

The DOE Clean Cities Program (2014) provides guidance on assessment, installation, and implementation of the WPC systems, which suggests to designate (or reserve) charging stations to PEVs and to remain PEVs charged throughout the entire working hours. The guidance has been widely adopted by employers for its easy implementation (CALSTART, 2013), which on the other hand limits the practice to workplaces with a small number of PEVs and the use of level 1 charging (DOE, 2014) due to its low equipment and installation cost. When a large number of PEVs are present, it is neither practical nor economical to continue this "reservedcharger" policy and PEVs will be first-come-first-serve. It is likely to defer some of employees from using PEVs because of the unsureness of securing a charger and the potential charging congestions (Motavalli, 2013). It is thereby crucial to develop a cost-effective decision making framework that provides optimal strategies in planning and operating the WPC system to satisfy all PEV charging demand without charging congestions.

To best utilize the WPC system, it is important to first stress the correlations between the technical aspects of relevant PEV charging technologies and demographic characteristics of PEV daily commuters. The technical aspects of charging methods include charging efficiency (miles boosted per hour charge), equipment and installation cost, and electricity consumption rate. Given a charging demand, a low power charging method (e.g., level 1 charger), though cheaper to set up, may need more chargers than a high power charging method (e.g., level 2 charger), though with a higher overall cost. The demographic characteristics of PEV impose heterogeneity in charging demands, which is largely caused by the variations in daily commute distances. In this study, the WPC should only be responsible for one-way work-to-home trips and operates within working hours. A charger may serve multiple PEVs during a day via vehicles swapping and these PEVs are charged in sequence. However, unlike public charging stations that provide "drive-through" charging services where a PEV driver may need multiple charging depending on the length of the trips, WPC offers destination charging and is unrealistic to assume that a PEV user may use multiple chargers for unnecessary hassles in vehicle swapping at workplace. A well-planned WPC strategy is considered as an effective means to better utilize charging resources and eventually resolve the charging congestions. The operational decisions on charging 
scheduling or assignment of PEVs to chargers rely on the planning decisions, such as number of chargers and charging methods deployed. Thus, both levels of decisions have to be made in an integrated modeling framework in order to achieve the overall cost effectiveness.

This study is the first research work undertaken that uses combinatorial optimization approaches to design WPC strategies at the lowest cost of equipment, installation, and operation while satisfying charging demand. We develop an integer program that takes into account the technical aspects of eligible charging methods and heterogeneous charging demand. The optimization framework simultaneously makes planning decisions on the number of chargers and their charging levels as well as assignments of PEVs to different charging stations.

The proposed optimization framework is essentially a resource allocation or knapsack problem, which studies how to assign limited resources in an economic way to satisfy demand and has been extensively researched (Luss, 1992) in a wide range of research topics, including emergency resource allocations (Sheu, 2007), wireless network construction (Letaief and Zhang, 2006), airspace (Kim and Hansen, 2013), and construction management (Hegazy, 1999). This work contributes to the literature on a new application of allocation of charging resources. In addition, this study enriches a vast body of literature on electric vehicle charging station location problems. There are three major series of studies: a) spatial economics models with an emphasis on analyzing station locations on spatial networks. This type of studies include node based demand models (Stephens-Romero et al., 2010, Frick et al., 2007, Frade et al., 2011, Ip et al., 2010), and flow based models, such as Flow Intercepting Facility Location Problem (FIFLP) (Hodgson, 1990, Berman et al., 1992, Boccia et al., 2009), the maximal-flow-coverage based Flow-Refueling Location Problem (FRLP) (Kuby and Lim, 2005, Kim and Kuby, 2012, Kim and Kuby, 2013, Upchurch et al., 2009) with applications in Alternative Fueling Station (AFS) problems (Kuby et al., 2009, Lim and Kuby, 2010, Zeng et al., 2010, Capar and Kuby, 2011), and the minimum-cost based flow based set-covering models (Wang, 2007, Wang and Lin, 2009, Wang, 2008, Wang and Lin, 2013, Wang and Wang, 2010, Li and Huang, 2014). Both the maximum-coverage and minimum-cost models are generalized (MirHassani and Ebrazi, 2013, Wen et al., 2013). b) travel-demand based models. Demand nodes are identified when cumulative traveled distances, calculated using an activity-based travel demand model, exceed a vehicle range. These demand nodes are then treated as candidate sites in a node-based location model, i.e., p-median, center, or maximum coverage models, and "best locations" are then determined through solving the optimization models (Chen et al., 2013, Dong and Lin, 2012, Dong et al., 2014, Xi et al., 2013). A more recent activity-based network design model (Kang et al., 2013, Kang and Recker, 2014, Jung et al., 2014) extends these models to explicitly model the interplays between the station siting strategies and traveler's scheduling and routing choices via integrating Household Activity Pattern Problem (HAPP) into Location-Routing Problem (LRP), which are particularly suitable for siting stations in urban areas based on daily trips. c) traffic flow based models. These models explicitly integrate the effects of traffic flows into the charging-location decisions on the network, including studies (He et al., 2013a, He et al., 2013b, He et al., 2014, Nie and Ghamami, 2013, He et al., 2013c).

Distinct from the prior research, this study is focused on allocation of charging resources and scheduling the use of the limited resources to satisfy charging demand for a workplace. We implement the optimization model with numerical examples that are based on national average data. The numerical results justify the proposed framework and highlight the social benefits (e.g., emission reductions) of WPC as an alternative to the current sustainable transportation programs, such as public transit and carpooling subsidies. The results provide managerial insights for DOE 
to educate interested companies and to provide them guidance on decision-making between WPC and other options.

The reminder of the paper is organized as follows. The details of the background of the WPC are provided in section 2. Section 3 presents the optimization framework. The data and results of numerical tests are presented in section 4 . We summarize the study with outlined future research in section 5 .

\section{BACKGROUND ON WORKPLACE CHARGING}

There is a collection of charging equipment in market (CALSTART, 2013). In this study, we only consider three most plausible levels of chargers for workplace charging, which are level 1, level 2 with low power (labeled as level 2L), and level 2 with median power (labeled as level 2M). High equipment cost is one reason to go with low power charger (compared to high amp level 2 or DC fast charger), while "hidden fees" such as frequent vehicle swapping which cost employers' time and labor is another consideration. The selected chargers' characteristics and equipment prices are summarized in Table 1. Note that there are many options in the market so that the equipment prices are stated in ranges. The table indicates clear tradeoffs between different charging levels. For example, the level 1 chargers feature the lowest charging intensity (measured in miles boosted by charging an hour) and power consumption but the lowest price while the level $2 \mathrm{M}$ chargers on the contrary feature the highest in all these aspects. Given a charging demand, using level $2 \mathrm{M}$ chargers, though capital intense, may reduce overall cost with fewer chargers.

\section{Place Tables 1 and 2 about here}

The installation is another substantial cost component of running the WPC system, which varies with labor costs, wiring conditions, etc. According to (Inside EVs, 2014, CALSTART, 2013), the installation cost can be broken down to seven major cost items as shown in Table 2. All the costs are in ranges. Except for the "sub-panel upgrade" cost, all other cost items are stated as per charger. It is assumed that the installation cost is identical for both Level $2 \mathrm{~L}$ and $2 \mathrm{M}$ charging methods. As installation costs vary in ranges and are substantial, we consider both the low and high installation costs in this study (see section 4 for details).

The operating cost of the WPC system in this paper mainly refers to the electricity cost. Depending on how the electricity is used and how much capacity is needed, electric utility is charged differently. In many cases, electricity use is metered based on the total consumption. The company only pays for the energy uses (measured in kilowatt-hour or $\mathrm{kWh}$ ) for charging. In other cases, the company may be billed based on the highest capacity (measured in kilowatt or $\mathrm{kW}$ ) required during the given billing period, typical a 15-minute interval during that cycle. This can be the case when a large number of vehicles charging during the same peak hours. In this study, we consider both types of electricity utility charges and analyze their effects separately.

Employees' daily commute distance is a crucial factor that drives the charging demand, and consequently affects the number of chargers and levels of chargers needed. We use the 2009 national household survey (RITA, 2003) on one-way-to-work commute distances as the basis of the distributions of PEV employees' work-to-home travel distances. The survey reports eight groups of distances with a five-mile interval as shown in Table 3 . The data indicate that on the national average, there are $68 \%$ of people driving less than 15 miles one-way to work, $22 \%$ of people driving between a range of 16 and 30 miles on-way to work, and $11 \%$ of people driving 
more than 30 miles one-way (we assume that the upper limit is 50 miles in this study). Based on this distribution, the total number of employees is distributed in proportion to the eight groups. For example, considering a company of 100 employees using PEVs to commute, we assume that there are 29 of them commuting less than 5 miles one-way, 22 commuting between 6 and 10 miles one-way, etc. Note that this is a national average distribution of one-way work commute distances. For different companies, the distribution of employees' commute distances could be dramatically different and an accurate estimate can be obtained through internal surveys (see an example in (CALSTART, 2013)). It is not of our intention in this study to provide consultation to a specific company. Instead, we aim to develop and justify a general WPC optimization framework that can be used for different sized companies.

Place Table 3 about here

\section{METHOD}

\subsection{A simple example illustration}

We use a simple example to illustrate how optimization based decisions are different from the current practice of the DOE's WPC guidance and how the cost of running a WPC can be reduced as a result of the new strategies. The proposed decision making framework allows swapping PEVs on a charger, which is distinct from the current DOE WPC guidance. For illustration purpose, we only consider three groups of employees and two types of charging technologies (see Table 4). The cost structure of charging methods is further simplified that the total cost of equipment, installation, and operation of level 1 and 2 chargers are respectively $c$ and $2 c$ per charger.

Place Table 4 about here

The results of optimization are reported in Table 5, compared with the results of the guidance ("No Optimization"). Without optimization, four level 1 and one level 2 chargers are needed to serve the five PEVs, given an 8-hour time window, which results in a total cost of $6 c$. Each PEV in groups \#1 and \#2 will be assigned to one of the four level 1 chargers, and the PEV in group \#3 will be assigned to the level 2 charger. When the time window is down to 6 hours, only the two level 1 chargers are applicable for the PEVs in group \#1, due to the charging durations. The other three PEVs will have to be served by the three level 2 chargers. The total cost increases to $8 c$. Again, each PEV is granted a full access to a charger throughout entire time window without a need of vehicle swapping. Turning to the results of the optimization, under 8hour time window, only one level 1 and one level 2 chargers are needed with a total cost of $3 c$. The level 1 charger serves the two PEVs in group \#1 while the one level 2 charger serves the two PEVs in group \#2 and one PEV in group \#3. All PEVs will take turns to charge. Under 6-hour time window, one more level 2 charger is needed makes the total cost increase to $5 c$. As seen, the optimized WPC strategies help reduce the total system cost in both cases. For larger numbers of PEVs, the optimal planning and operational strategy will have to be determined through solving the optimization model proposed in section 3.2.

Place Table 5 about here 


\subsection{Optimization framework}

The WPC optimization framework entails the number of chargers and types of charging methods to use as well as detailed assignment of PEVs to chargers. The proposed optimization framework is formulated as an integer program, which is general and can be applied to different sized companies. The objective is to minimize the total annualized cost of equipment and installation, and annual operating cost. There are a number of major assumptions. First, a vehicle is only charged to the extent to cover the work-to-home trip. Second, each charger is equipped with only one outlet, thus can only charge one PEV at a time. However, as chargers with two outlets emerge in the market, this assumption can be relaxed in the future study, which however will not change the structure of the proposed model. Third, it is realistic that one charger may serve multiple PEVs, but one PEV will be served by at most one charger. Fourth, the power charged and depleted is proportional to travel distance in miles. Last, the electricity consumption charge is constant (e.g., an average of peak and off-peak charges) during working hours. The parameters and variables used in the model are first introduced, followed by the complete formulation in (1)(10). We use lower-case letters for variables and upper-case letters for parameters.

Sets:

$i$ : $\quad i^{\text {th }}$ charger, $i=1, \ldots, I$.

$k$ : $\quad$ a charging level, $k \in K=\{$ level 1 , level $2 \mathrm{~L}$, and level $2 \mathrm{M}\}$

$d$ : $\quad$ a group of one-way commute (work-to-home) distances (see Table 3), $d \in D$.

\section{Parameters:}

$C_{k}^{F} \quad$ equipment cost (\$) of level $k$ charger, $k \in K$.

$C_{k}^{I_{F}} \quad$ fixed installation cost (\$) of level $k$ charger, $k \in K$.

$C_{k}^{I_{V}} \quad$ variable installation cost (\$) of level $k$ charger, $k \in K$.

$C^{B} \quad$ electricity cost $(\$ / \mathrm{kWh})$ - consumption charge.

$E_{k} \quad$ power consumption of using level $k$ charger $(\mathrm{kW}), k \in K$.

$V_{d} \quad$ number of drivers within the distance range $d$.

$H_{d k} \quad$ charging duration (hours) of using level $k$ charger to charge a PEV of distance range $d$.

TW time window.

$W D$ number of workdays per year.

$\alpha \quad$ annualized factor.

\section{Variables:}

$x_{i k} \quad=1$ if level $k$ charging is used at the $i^{\text {th }}$ charging station; 0 otherwise.

$y_{i d k} \quad$ integer, number of PEVs of distance range $d$ served by the level $k$ charging at the $i^{\text {th }}$ charging station.

$z_{k} \quad=1$ if level $k$ charging is used; 0 otherwise

\section{Model formulation:}




$$
\begin{array}{ll}
\text { Minimize } \alpha \sum_{i=1 . I} \sum_{k \in K} & C_{k}^{F} x_{i k}+\alpha\left(\sum_{k \in K} C_{k}^{I_{F}} z_{k}+\sum_{i=1 . I} \sum_{k \in K} C_{k}^{I_{V}} x_{i k}\right)+\sum_{d \in D} \sum_{i=1 . I} \sum_{k \in K} E_{k} H_{d k} C^{B} y_{i d k} W D \\
\text { Subject to } & y_{i d k} \leq \bar{M} x_{i k}, i=1, \ldots, I, \forall d \in D, k \in K \\
& \sum_{k \in K} x_{i k} \leq \sum_{k \in K} x_{(i-1) k}, i=2, \ldots, I \\
& \sum_{d \in D} H_{d k} y_{i d k} \leq T W, i=1, \ldots, I, \forall k \in K \\
& \sum_{i=1 . . I} \sum_{k \in K} y_{i d k} \geq V_{d}, \forall d \in D \\
& \sum_{k \in K} x_{i k} \leq 1, i=1, \ldots, I \\
& \sum_{k \in K} x_{i k} \leq M z_{k}, \forall k \in K \\
& x_{i k}=\{0,1\}, i=1, \ldots, I, \forall k \in K \\
& y_{i d k} \in \mathbb{Z}, i=1, \ldots, I, \forall d \in D, k \in K \\
& z_{k}=\{0,1\}, \forall k \in K
\end{array}
$$

The objective function (1) is to minimize the total annualized cost of equipment (expressed in the first term), installation (the second term), and operation (the third term). Note that in the installation cost, the term $\sum_{k \in K} C_{k}^{I_{F}} z_{k}$ is to capture the cost of "sub-panel upgrade" (see Table 2), which only relates to the levels of chargers to use regardless of the number of chargers. The variable $z$ is defined in constraints (7). The term $\sum_{i=1 . . I} \sum_{k \in K} C_{k}^{I_{V}} x_{i k}$ in the installation cost accounts for other cost items that are dependent on both the levels and number of chargers. The operation cost in this model is based on the electricity consumption charge $(\$ / \mathrm{kWh})$. In the sensitivity analysis (section 4.3$)$, we also consider demand charge $(\$ / \mathrm{kW})$ with simple modifications.

Inequality set (2) is a logic constraint set, stating that no PEV is assigned to a charger unless it operates, where $\bar{M}$ is a sufficiently large number. Note that as the model is to minimize WPC system cost, a large number should be used as the cardinality of charger set $I$ (e.g., a total number of PEV users) to ensure that there are sufficient chargers. Constraint set (3) imposes an order constraint, stating that the $i^{\text {th }}$ charger will not be used until the $(i-1)^{\text {th }}$ charger has been used. This is an auxiliary constraint, which is to the retrieve optimal deployment strategies and will not alter the same optimal solutions, due to the assumption of identical technical aspects of chargers for a certain level and the use of average electricity consumption charge. Constraints (4) assure that each charger operates within the time windows. Constraints (5) ensure that all charging demands will be satisfied. Constraints (6) require that a charger can only be equipped with at most one charging level. Constraint set (7) states a logic relationship between variables $x$ and $z$, 
which defines variable $z$ for the objective function to capture the cost item "sub-panel upgrade". Constraints (8)-(10) define integer and binary variables.

\section{NUMERICAL EXAMPLES}

\subsection{Data Preparations}

The technical aspects of charging methods and employee's commute distances have been provided in Tables 1-3. The charging durations $\left(H_{d k}\right)$ of different charging levels for PEVs from different distance groups are derived by using the equation $H_{d k}=\left\lceil T_{d} / R_{k}\right\rceil$, where $T_{d}$ is the upper bounds of distance groups (see Table 3 ) and $R_{k}$ is the recharging rate (miles per hour boosted in Table 1) of level $k$ charger. We use the upper bounds of commute distances to ensure that PEVs are charged sufficiently and to introduce a lead-time for vehicle swapping. The derived charging durations are shown in Table 6. For example, the PEV drivers in distance group \#2 have a maximum 10-mile commute distance (see Table 3) and thus spend 2.5 hours, 0.83 hours, and 0.45 hours of charging on the levels $1,2 \mathrm{~L}$, and $2 \mathrm{M}$ chargers respectively. The charging hours are rounded to 3,1 , and 1 hours in this study to make the real-world implementation plausible.

\section{Place Table 6 about here}

The capital costs are annualized with an assumed 10-year useful life and a 10\% interest rate, and the annualized cost factor is calculated using engineering economic formula $(\mathrm{A} / \mathrm{p}, 10 \%$, $10)=0.1627$. In this study, we consider the average of $\$ 0.1275 / \mathrm{kWh}$ in a range between $\$ 0.09$ and $\$ 0.3$ per kWh (Williams and DeShazoa, 2014) as the electricity consumption charge rate. This can be extended to explicitly capture the variations in the charge rates over peak, off-peak and shoulder hours, which leads to a more detailed scheduling modeling as part of our future work. The analysis on demand charge is provided in section 4.3.

\subsection{Baseline Results}

All numerical examples were programmed using AMPL (Fourer et al., 2011) and solved by the commercial solver CPLEX. A hypothetical case study is provided, in which we assumes there is a medium-sized company with ten employees who use PEVs for daily commute. We assume that the distribution of the ten employees' one-way commute distances follows the national average distribution (Table 3). The equipment and installation costs are adopted from Tables 1 and 2, respectively. We consider both low and high installation costs coupled with six(6)-hour and eight(8)-hour time windows, which results in four different cases: 8-hour time window with low installation cost, 6-hour time window with low installation cost, 8-hour time window with high installation cost, 6-hour time window with high installation cost. The model provides the most cost effective strategies in planning and operating the WPC system while satisfying the ten employees' charging demand (one-way only).

The resulting WPC strategies, including both planning and operational decisions, are presented in Table 7 . The results show the numbers of chargers needed for different time windows, the assignment of PEVs from different groups to different chargers, charging levels of each charger, and the hours of charging on each charger. Note that the number and levels of chargers are identical for both levels of installation costs for a given time window, which may be 
due to a relatively small number of PEVs considered. As shown in sensitivity analysis, the strategies can vary with the installation costs when larger PEV populations are considered.

Place Table 7 about here

The decisions on the assignments of chargers to PEVs from different distance groups (i.e., \#1-8) are indicated by zero or one in the table with one indicating that a charger is assigned to a group of PEVs; zero otherwise. For example, the row of "charger \#1" under 6-hour time window shows that this charger is used to charge two PEVs from group \#2. Since this is a level 1 charger (indicated by the column "Level of chargers"), it takes three hours to complete charging a PEV of group \#2 (according to Table 6). As each charger is equipped with only one outlet, these two PEVs are charged in sequence, with a total of 6 hours of charging. The row with the heading "Total PEVs" shows the total numbers of PEVs served by different chargers, which match the numbers of PEVs in each distance group. The results demonstrate that the number of chargers and charging levels correlate, which requires the planning and scheduling decisions to be made simultaneously.

Comparing the results of 6-hour time window with the 8-hour time window, the total number of chargers is reduced and each charger serves more PEVs due to the relaxed time window. For example, five chargers are needed under 6-hour time window, in which the charger \#5 is only used for 2 hours. Under 8-hour time window, only three chargers are needed, two of which are utilized for 8 hours and the other one is used for 7 hours. The total number of charging hours is counterintuitively longer under 6-hour time window of 26 hours than the 23 hours under 8-hour time window, which is because more chargers are involved under the 6-hour time window. The table also indicates that a particular charger may be used to serve multiple PEVs from different distance groups and similarly PEVs from a particular distance group may be served by different chargers.

Place Figure 1 about here

The resulting total costs are respectively $\$ 4,956, \$ 5,495, \$ 7,575$, and $\$ 9,123$ for the cases of 8-hour time window with low installation cost, 6-hour time window with low installation cost, 8-hour time window with high installation cost, 6-hour time window with high installation cost. It is important to stress that following the current practice of designating charging stations to PEVs the total cost is respectively $\$ 6,991, \$ 7,762, \$ 13,141$, and $\$ 14,693$ for the four cases, which are 40\%-70\% higher than our optimized WPC systems. The cost savings by using our proposed model are largely attributed to the utilization of different charging technologies and to taking advantage of geographically distributed PEV users.

We further break the total cost down to three components: the annualized equipment cost, annualized installation cost, and annual electricity cost, displayed by the four stacked bars in Figure 1. The results first indicate that all three cost items are substantial. The major cost of running the WPC system is not buying the equipment's but having the chargers installed and getting the electricity to the charging stations. A wider time-window (comparing 8 hours to 6 hours) is more cost effective, which represents a total cost reduction respectively by $11 \%$ $((\$ 5,495$ - \$4,965)/\$4,965) and 20\% ((\$9,123 - \$7,575)/ \$7,575) for the low and high installation costs, mainly due to the reduced number of chargers used. The annual electricity cost under 6 hour time window is marginally lower than the cost under 8 hour time window, although we 
have seen that the operating hours are reversely longer by three hours. This is because the power consumption of level $2 \mathrm{M}$ is five times higher than the power consumption of level 1 (see Table 1 ) and the electricity cost of running an hour on the level $2 \mathrm{M}$ charger outweighs the cost of running on the level 1 charger for additional four hours.

\subsection{Sensitivity Analyses}

We conduct a set of sensitivity analyses to understand the impacts of the PEV population size and demand charge scheme on the WPC strategies. The results are presented in this section.

The PEV population size: We run the model for four other different PEV population sizes (i.e., 20, 50, 100, and 200). The resulting numbers of chargers and the associated charging levels are plotted in Figure 2. The two figures on each row [i.e., (a)-(b) and (c)-(d)] show the strategies under the same time window (i.e., six or eight hours). Through the comparisons, we notice that the higher installation cost results in the use of fewer level 1 chargers and more level $2 \mathrm{M}$ chargers with the increase of population sizes. This is because the increase in equipment cost of using more powerful chargers offsets the decrease in installation and operating costs. The comparisons of the plots in each column [(a)-(c) and (b)-(d)] indicate that, as seen before, a narrower time window requires more chargers as each charger serves fewer PEVs a day. For example, by comparing (b) with (d), both level 1 and level $2 \mathrm{M}$ chargers increase when the time window is suppressed from eight to six hours for the same charging demand. Such goal can also be achieved by using more high-power (level 2M) and fewer low-power (level 1) chargers, which is the case for low installation cost [(a)-(c)]. The results also imply that optimizing a WPC strategy is not a simple process of adding chargers with the increase of charging demand. Instead, it requires re-optimization of the entire system for the best economic performance. The corresponding annual electricity consumptions are plotted in Figure 3. In general, a narrower time window or higher installation cost increases the power consumption due to the use of more level $2 \mathrm{M}$ chargers.

\section{Place Figures 2 and 3 about here}

Demand Charge scheme: By definition, demand charge is the charge based on the highest demand happens during the billing cycle. In other words, it happens when the demand is higher than the average needs, such as, summer time. The 'high' demand for 15 minutes in that month or every day is used as a charge basis. It is difficult to determine a certain level of the demand charge since it depends on the company size and their average needs. The demand charge rate varies in a diverse range depending on region and utility providers. In this study, we assume the demand charge only incurs in summer for 70 workdays with a price ranged from $\$ 7.5$ to $\$ 12 / \mathrm{kW}$ (denoted by $C^{B D}$ ) with an increment of 50 cents $/ \mathrm{kW}$. This price range is decided based on the demand charge rates provided by utility companies from different regions. The remaining 190 workdays are based on regular utility consumption charge. We modify the electricity cost term in

the objective function as: $\sum_{d \in D} \sum_{i=1 . . I} \sum_{k \in K}\left(E_{k} C^{B D} y_{i d k} \times 70+E_{k} H_{d k} C^{B} y_{i d k} \times 190\right)$. Note that under demand charge, the electricity cost is independent of the number of working hours.

Place Figure 4 about here 
We run the revised optimization model only for 50, 100, and 200 PEVs, when electricity consumption is sufficiently large to justify the use of demand charge scheme. We only consider the 8-hour time window and low installation cost in this analysis. The results plotted in Figure 4 show that the total costs increase with the charge rates from $\$ 7.5$ to $\$ 12$ per $\mathrm{kW}$ with the consumption charge fixed at $\$ 0.1275 / \mathrm{kWh}$, identical to the baseline. The straight lines in the figure imply that for a given PEV population size the change of demand charge rates does not alter the WPC strategies (i.e., identical number and levels of chargers) and the total annual cost increases only due to the growth of demand charge rate. Further investigations reveal that the resulting WPC strategies are those with the lowest electricity cost, regardless of demand charge rates. This is because the electricity cost dominates the total cost, accounting for $88 \%-92 \%$. Comparing with the baseline results, the demand charge makes the total system cost at least four times higher in the correspondents. More PEVs require larger electricity capacity and thus result in higher demand charge per $\mathrm{kW}$, which explains the steeper slopes with larger PEV populations.

\subsection{Analysis of Cost of WPC as an Alternative to Public Transit Program}

We analyze the potential of the WPC as an alternative sustainable transportation program. It is important to understand the difference in the cost compared with other sustainable transportation options, such as public transit. In this study, we consider both diesel and CNG buses and compare them to the WPC program based on both the economic and social costs. The social cost is measured as the dollar assigned to ton of each end-use pollutant type (\$/ton). The social cost of PEVs is considered as zero in this study since the model we proposed ensures that PEVs have enough power to complete the work-to-home trips. Using a 2010 car and transit bus (both diesel and compressed natural gas (CNG)) as examples, Table 8 presents the rates of major emissions and associated social costs for each pollutant type. Emission rates are based on Argonne' most current GREET model (Argonne National Laboratory, 2014) and social costs are based on (NERA Economic Consulting, 2008). Bus emission rates are converted to gram/passenger mile, using the factor of one transit-bus mile equivalent to 8.73 passenger miles in 2010 (Davis, 2013).

Place Table 8 about here

We assume that the average public transit subsidy for each employee is $\$ 120 /$ month $^{1}$. Figure 5 compares the annualized cost of incentivizing public transit and investing in WPCs for the five different sizes of PEV populations. Even without social cost (only accounting for 3.4\%$4.1 \%$ of the total cost), the employees' public transit incentive still greatly exceeds the annualized cost of running a WPC system even considering the scenario of high installation cost.

Place Figure 5 about here

\section{CONCLUSIONS}

We develop an optimization framework for WPC strategies, which entails the number and levels of chargers to install and operate while satisfying charging demand of employees' PEVs. This is

\footnotetext{
${ }^{1}$ This $\$ 120$ /month may cover a round trip to work while the WPC only includes electricity usage for one-way workto-home trip to cover the least charging needs regardless of how much a PEV is charged before leaving home.
} 
the first study that uses systems approach to design WPC strategies. The proposed optimization framework explicitly considers the correlations between different levels of charging technology, employee's demographic spatial distributions, and physical constraints (e.g., time windows) from a system's perspective. The study develops a general decision making framework that provides the WPC strategies at least lifetime cost while satisfying all charging demand of PEVs.

We demonstrate the applicability and generality of the optimization framework using numerical examples which are based on average national data (for both charging methods and the travel distribution pattern). The results of numerical example of a median-sized company with 10 PEVs show that the proposed optimization framework reduces the total cost of running a WPC by up to 70\%, compared to the DOE's guidance (non-optimization based method). Through sensitivity analyses, we understand that the WPC strategy is sensitive to the time window and installation cost. Moreover, it is dominated by PEV population and highly impacted by the electricity charging scheme. Achieving an optimal WPC strategy is not a simple process of adding or removing chargers with the change of number of PEVs. Instead, it requires to reoptimize the entire WPC system for the most economic solutions. With a 10-year lifetime, the WPC can be a viable alternative sustainable transportation option to the traditional public transit subsidy program.

There are several immediate extensions to this study. First, battery electric vehicles (BEVs) and plug-in hybrid electric vehicles (PHEVs) are not explicitly distinguished in term of charging rates. In the future work, we may need to adjust the model to reflect the priorities of charging BEVs over PHEVs when the charging resources are limited. Second, a charging station can have multiple outlets (e.g., two) so that multiple vehicles can be charged at the same time. This realistic consideration can lead to a more cost effective solution. Also related, a more detailed scheduling of charging will be needed to capture the effects of electricity consumption rate fluctuating during the course of a day. To appropriately reflect the changes, we will modify the models and collect relevant data, which may increase the model complexity as a mixed integer program. The algorithmic development may also be of importance in the future to tackle the computational burden. Third, it would also be of great interest to consider other policies, parallel to the WPC, such as recovering electricity usage (utility bill) from employees as another option to reduce the annualized investment while in the same time being qualified for DOE' WPC pledge.

\section{Acknowledgements}

The effort of Yan Zhou of Argonne National Laboratory is supported by the Vehicle Technology Office, Energy Efficiency and Renewable Energy Office. The submitted manuscript has been created by UChicago Argonne, LLC, Operator of Argonne National Laboratory ("Argonne"). Argonne, a U.S. Department of Energy Office of Science laboratory, is operated under Contract No. DE-AC02-06CH11357. The U.S. Government retains for itself, and others acting on its behalf, a paid-up nonexclusive, irrevocable worldwide license in said article to reproduce, prepare derivative works, distribute copies to the public, and perform publicly and display publicly, by or on behalf of the Government.

\section{REFERENCE}

Argonne National Laboratory. 2014. The Greenhouse Gases, Regulated Emissions, and Energy Use in Transportation Model (GREET1_2013) [Online]. Available: https://greet.es.anl.gov/main [Accessed July 29 2014]. 
Berman, O., Larson, R. C. \& Fouska, N. 1992. Optimal Location of Discretionary Service Facilities. Transportation Science, 26, 201-211.

Boccia, M., Sforza, A. \& Sterle, C. 2009. Flow Intercepting Facility Location: Problems, Models and Heuristics. Journal of Mathematical Modelling and Algorithms, 8, 35-79.

CALSTART. 2013. Best Practices for Workplace Charging [Online]. Available: http://www.calstart.org/Libraries/Publications/Best_Practices_for_Workplace_Charging.s flb.ashx [Accessed July 31 2014].

Capar, I. \& Kuby, M. 2011. An efficient formulation of the flow refueling location model for alternative-fuel stations. IIE Transactions, 44, 622-636.

Chen, T. D., Kockelman, K. M. \& Khan, M. The electric vehicle charging station location problem: A parking-based assignment method for Seattle. Transportation Research Board 92nd Annual Meeting, 2013. 13-1254.

Davis, S. C., et al 2013. Transportation Energy Data Book: Edition 32. Oak Ridge National Laboratory. Oak Ridge, Tenn.

DOE. 2014. Vehicle Technologies Office: EV Everywhere Workplace Charging Challenge [Online]. Available: http://energy.gov/eere/vehicles/vehicle-technologies-office-eveverywhere-workplace-charging-challenge [Accessed July 31 2014].

DOE Clean Cities Program. 2014. Plug-in Electric Vehicle Handbook for Workplace Charging Hosts [Online]. Available:

http://www.afdc.energy.gov/uploads/publication/pev_workplace_charging_hosts.pdf [Accessed July 31 2014].

Dong, J. \& Lin, Z. 2012. Within-day recharge of plug-in hybrid electric vehicles: Energy impact of public charging infrastructure. Transportation Research Part D: Transport and Environment, 17, 405-412.

Dong, J., Liu, C. \& Lin, Z. 2014. Charging infrastructure planning for promoting battery electric vehicles: An activity-based approach using multiday travel data. Transportation Research Part C: Emerging Technologies, 38, 44-55.

Fourer, R., Gay, D. M. \& Kernighan, B. W. 2011. AMPL: A Modeling Language for Mathematical Programming (Second Edition), Belmont, CA, Brooks/Cole.

Frade, I., Ribeiro, A., Gonçalves, G. \& Antunes, A. 2011. Optimal Location of Charging Stations for Electric Vehicles in a Neighborhood in Lisbon, Portugal. Transportation Research Record: Journal of the Transportation Research Board, 2252, 91-98.

Frick, M., Axhausen, K. W., Carle, G. \& Wokaun, A. 2007. Optimization of the distribution of compressed natural gas $(\mathrm{CNG})$ refueling stations: Swiss case studies. Transportation Research Part D: Transport and Environment, 12, 10-22.

He, F., Wu, D., Yin, Y. \& Guan, Y. 2013a. Optimal deployment of public charging stations for plug-in hybrid electric vehicles. Transportation Research Part B: Methodological, 47, 87-101.

He, F., Yin, Y. \& Lawphongpanich, S. 2014. Network equilibrium models with battery electric vehicles. Transportation Research Part B: Methodological, 67, 306-319.

He, F., Yin, Y., Wang, J. \& Yang, Y. 2013b. Sustainability SI: Optimal Prices of Electricity at Public Charging Stations for Plug-in Electric Vehicles. Networks and Spatial Economics, $1-24$.

He, F., Yin, Y. \& Zhou, J. 2013c. Integrated pricing of roads and electricity enabled by wireless power transfer. Transportation Research Part C: Emerging Technologies, 34, 1-15. 
Hegazy, T. 1999. Optimization of Resource Allocation and Leveling Using Genetic Algorithms. Journal of Construction Engineering and Management, 125, 167-175.

Hodgson, M. J. 1990. A Flow-Capturing Location-Allocation Model. Geographical Analysis, 22, 270-279.

Inside EVs. 2014. How Much Do Public And Home EV Charging Stations Really Cost? [Online]. Available: http://insideevs.com/how-much-do-public-and-home-ev-charging-stationsreally-cost/ [Accessed July 29, 2014.

Ip, A., Fong, S. \& Liu, E. Optimization for allocating BEV recharging stations in urban areas by using hierarchical clustering. Advanced Information Management and Service (IMS), 2010 6th International Conference on, 2010. IEEE, 460-465.

Jung, J., Chow, J. Y. J., Jayakrishnan, R. \& Park, J. Y. 2014. Stochastic dynamic itinerary interception refueling location problem with queue delay for electric taxi charging stations. Transportation Research Part C: Emerging Technologies, 40, 123-142.

Kang, J. E., Chow, J. Y. J. \& Recker, W. W. 2013. On activity-based network design problems. Transportation Research Part B: Methodological, 57, 398-418.

Kang, J. E. \& Recker, W. 2014. Strategic Hydrogen Refueling Station Locations with Scheduling and Routing Considerations of Individual Vehicles. Transportation Science, 0 .

Kim, A. \& Hansen, M. 2013. A framework for the assessment of collaborative en route resource allocation strategies. Transportation Research Part C: Emerging Technologies, 33, 324339.

Kim, J.-G. \& Kuby, M. 2013. A network transformation heuristic approach for the deviation flow refueling location model. Computers \& Operations Research, 40, 1122-1131.

Kim, J. G. \& Kuby, M. 2012. The deviation-flow refueling location model for optimizing a network of refueling stations. International Journal of Hydrogen Energy, 37, 5406-5420.

Kuby, M. \& Lim, S. 2005. The flow-refueling location problem for alternative-fuel vehicles. Socio-Economic Planning Sciences, 39, 125-145.

Kuby, M., Lines, L., Schultz, R., Xie, Z., Kim, J.-G. \& Lim, S. 2009. Optimization of hydrogen stations in Florida using the Flow-Refueling Location Model. International Journal of Hydrogen Energy, 34, 6045-6064.

Letaief, K. B. \& Zhang, Y. J. 2006. Dynamic multiuser resource allocation and adaptation for wireless systems. Wireless Communications, IEEE, 13, 38-47.

Li, S. \& Huang, Y. 2014. Heuristic approaches for the flow-based set covering problem with deviation paths. Transportation Research Part E: Logistics and Transportation Review, 72, 144-158.

Lim, S. \& Kuby, M. 2010. Heuristic algorithms for siting alternative-fuel stations using the Flow-Refueling Location Model. European Journal of Operational Research, 204, 5161.

Luss, H. 1992. Minimax resource allocation problems: Optimization and parametric analysis. European Journal of Operational Research, 60, 76-86.

MirHassani, S. A. \& Ebrazi, R. 2013. A Flexible Reformulation of the Refueling Station Location Problem. Transportation Science, 47, 617-628.

Motavalli, J. 2013. 6 Workplace Chargers, 26 Drivers: A California Company's Etiquette Solution [Online]. Available: http://www.plugincars.com/6-workplace-chargers-26drivers-california-companys-etiquette-solution-129143.html [Accessed August 25 2014]. 
NERA Economic Consulting 2008. Evaluation of NHTSA's Benefit-Cost Analysis of 2011-2015 CAFE Standards. Alliance of Automobile Manufacturers.

Nie, Y. \& Ghamami, M. 2013. A corridor-centric approach to planning electric vehicle charging infrastructure. Transportation Research Part B: Methodological, 57, 172-190.

Pearre, N. S., Kempton, W., Guensler, R. L. \& Elango, V. V. 2011. Electric vehicles: How much range is required for a day's driving? Transportation Research Part C: Emerging Technologies, 19, 1171-1184.

Plugin America. 2014. Accessory Tracker [Online]. Available: http://www.pluginamerica.org/accessories [Accessed July 29 2014].

RITA. 2003. On a typical day, how many miles one-way do you travel from home to work? [Online]. US DOT. Available: http://www.rita.dot.gov/bts/sites/rita.dot.gov.bts/files/publications/omnistats/volume_03 issue_04/html/figure_02.html [Accessed July 25 2014].

Sheu, J.-B. 2007. An emergency logistics distribution approach for quick response to urgent relief demand in disasters. Transportation Research Part E: Logistics and Transportation Review, 43, 687-709.

Stephens-Romero, S. D., Brown, T. M., Kang, J. E., Recker, W. W. \& Samuelsen, G. S. 2010. Systematic planning to optimize investments in hydrogen infrastructure deployment. International Journal of Hydrogen Energy, 35, 4652-4667.

Upchurch, C., Kuby, M. \& Lim, S. 2009. A Model for Location of Capacitated Alternative-Fuel Stations. Geographical Analysis, 41, 85-106.

Wang, Y.-W. 2007. An optimal location choice model for recreation-oriented scooter recharge stations. Transportation Research Part D: Transport and Environment, 12, 231-237.

Wang, Y.-W. 2008. Locating battery exchange stations to serve tourism transport: A note. Transportation Research Part D: Transport and Environment, 13, 193-197.

Wang, Y.-W. \& Lin, C.-C. 2013. Locating multiple types of recharging stations for batterypowered electric vehicle transport. Transportation Research Part E: Logistics and Transportation Review, 58, 76-87.

Wang, Y.-W. \& Wang, C.-R. 2010. Locating passenger vehicle refueling stations. Transportation Research Part E: Logistics and Transportation Review, 46, 791-801.

Wang, Y. W. \& Lin, C. C. 2009. Locating road-vehicle refueling stations. Transportation Research Part E-Logistics and Transportation Review, 45, 821-829.

Wen, M., Laporte, G., Madsen, O. B. G., Norrelund, A. V. \& Olsen, A. 2013. Locating replenishment stations for electric vehicles: application to Danish traffic data. J Oper Res Soc, - .

Williams, B. \& DeShazoa, J. 2014. Pricing Workplace Charging: Financial Viability and Fueling Costs. Transportation Research Board 93rd Annual Meeting.

Xi, X., Sioshansi, R. \& Marano, V. 2013. Simulation-optimization model for location of a public electric vehicle charging infrastructure. Transportation Research Part D: Transport and Environment, 22, 60-69.

Zeng, W., Castillo, I. \& Hodgson, M. J. 2010. A Generalized Model for Locating Facilities on a Network with Flow-Based Demand. Networks and Spatial Economics, 10, 579-611. 


\section{List of Tables}

Table 1. EV Charging Options

Table 2. Charger Installation Cost $(\$)$

Table 3. Travel Statistics

Table 4. Data for the Illustrative Example

Table 5. Results of the Example

Table 6. Charging Durations (Hours) for Different Groups of PEVs

Table 7. Assignments of PEVs to Chargers

Table 8. Major Emission Rates and Social Cost

\section{List of Figures}

Figure 1. Breakdowns of the total annualized costs of WPC for ten PEVs.

Figure 2. The effects of number of PEVs on the number of chargers installed

Figure 3. The effects of number of PEVs on annual electricity consumption (kWh)

Figure 4. Total annual costs under different demand charge rates.

Figure 5. Annualized public transit incentive versus annualized WPC cost 
Table 1. EV Charging Options

\begin{tabular}{l|llllllll}
\hline $\begin{array}{l}\text { Charging } \\
\text { methods }\end{array}$ & $\begin{array}{l}\text { Continuous } \\
\text { Amps }\end{array}$ & $\begin{array}{l}\text { Max } \\
\text { Amps }\end{array}$ & Volte & $\begin{array}{l}\text { Continuous } \\
\text { Power (kw) }\end{array}$ & $\begin{array}{l}\text { Max Power } \\
\text { (kw) - used } \\
\text { for model }\end{array}$ & $\begin{array}{l}\text { Boosted Miles } \\
\text { per charging } \\
\text { (miles/hr) }\end{array}$ & $\begin{array}{l}\text { Price } \\
\text { range (\$) }\end{array}$ & $\begin{array}{l}\text { Used for } \\
\text { model (\$) }\end{array}$ \\
\hline Level 1 & 12 & 15 & 120 & 1.4 & 1.8 & 4 & $400-2500$ & $\$ 600$ \\
Level 2L & 20 & 30 & 240 & 4.8 & 7.2 & 12 & $500-5000$ & $\$ 700$ \\
Level 2M & 30 & 40 & 240 & 7.2 & 9.6 & 22 & $500-5000$ & $\$ 1,000$ \\
\hline
\end{tabular}

Sources: (Plugin America, 2014)

Table 2. Charger Installation Cost $(\$)$

\begin{tabular}{l|llll}
\hline Components & \multicolumn{2}{|l}{ Level } & Charger & \multicolumn{2}{l}{ Level 2 Charger } \\
& Low & High & Low & High \\
\hline sub-panel upgrade* & 1000 & 2000 & 1000 & 2000 \\
Siting - Pad mount & 100 & 800 & 800 & 2000 \\
Siting - Feeder and pole & 200 & 1000 & 800 & 3000 \\
Termination of fusible & 300 & 800 & 1000 & 3000 \\
feeding to PEVs & & & & \\
Saw cutting and & 500 & 1000 & 1000 & 3000 \\
Trenching & & & & \\
Conduit and wiring & 200 & 800 & 500 & 1000 \\
\hline
\end{tabular}

*Note: this cost is regardless of the number of charging stations installed.

Source: (Inside EVs, 2014, CALSTART, 2013) 
Table 3. Travel Statistics

\begin{tabular}{l|ll}
\hline Group & Statistics & Miles traveled (One-way) to work (miles) \\
\hline 1 & $29 \%$ & $1-5$ \\
2 & $22 \%$ & $6-10$ \\
3 & $17 \%$ & $11-15$ \\
4 & $10 \%$ & $16-20$ \\
5 & $7 \%$ & $21-25$ \\
6 & $5 \%$ & $26-30$ \\
7 & $3 \%$ & $30-35$ \\
8 & $8 \%$ & $>35$ (assume up to 50 miles) \\
\hline
\end{tabular}

Source: (RITA, 2003)

Table 4. Data for the Illustrative Example

\begin{tabular}{l|llll}
\hline \multirow{2}{*}{ Group ID } & $\begin{array}{l}\text { Miles } \\
\text { traveled } \\
\text { (one-way) }\end{array}$ & $\begin{array}{l}\text { Number of } \\
\text { employees in } \\
\text { each group }\end{array}$ & \multicolumn{2}{l}{$\begin{array}{l}\text { Charging durations } \\
\text { (hours) to complete a } \\
\text { full recharge }\end{array}$} \\
\hline 1 & 15 & 2 & 3 & Level 1 \\
2 & 35 & 2 & 7 & Level 2 \\
3 & 50 & 1 & 10 & 3 \\
\hline
\end{tabular}

Table 5. Results of the Example

\begin{tabular}{l|lll|lll}
\hline \multirow{2}{*}{$\begin{array}{l}\text { Time window } \\
\text { (hours) }\end{array}$} & \multicolumn{3}{|c|}{ Optimization } & \multicolumn{3}{c}{ Guidance (Non-optimization) } \\
\cline { 2 - 7 } 8 & Level 1 & Level 2 & Total cost & Level 1 & Level 2 & Total cost \\
6 & 1 & 1 & $3 \mathrm{c}$ & 4 & 1 & $6 \mathrm{c}$ \\
\hline
\end{tabular}


Table 6. Charging Durations (Hours) for Different Groups of PEVs

\begin{tabular}{l|lll}
\hline Distance Group ID & Level 1 & Level 2L & Level 2M \\
\hline 1 & 2 & 1 & 1 \\
2 & 3 & 1 & 1 \\
3 & 4 & 2 & 1 \\
4 & 5 & 2 & 1 \\
5 & 7 & 3 & 2 \\
6 & 8 & 3 & 2 \\
7 & 9 & 3 & 2 \\
8 & 13 & 5 & 3 \\
\hline
\end{tabular}

Table 7. Assignments of PEVs to Chargers

\begin{tabular}{|c|c|c|c|c|c|c|c|c|c|c|c|}
\hline \multirow[t]{2}{*}{$\begin{array}{l}\text { Time } \\
\text { windows }\end{array}$} & \multirow[t]{2}{*}{ Charger ID } & \multicolumn{8}{|c|}{$\begin{array}{l}\text { PEVs in eight travel distance } \\
\text { groups }\end{array}$} & \multirow{2}{*}{$\begin{array}{l}\text { Levels of } \\
\text { chargers }\end{array}$} & \multirow{2}{*}{$\begin{array}{l}\text { Hours of } \\
\text { charging }\end{array}$} \\
\hline & & 1 & 2 & 3 & 4 & 5 & 6 & 7 & 8 & & \\
\hline \multirow[t]{6}{*}{ 6-hour } & 1 & 0 & 2 & 0 & 0 & 0 & 0 & 0 & 0 & Level 1 & 6 \\
\hline & 2 & 1 & 0 & 1 & 0 & 0 & 0 & 0 & 0 & Level 1 & 6 \\
\hline & 3 & 1 & 0 & 1 & 0 & 0 & 0 & 0 & 0 & Level 1 & 6 \\
\hline & 4 & 0 & 0 & 0 & 1 & 1 & 0 & 0 & 1 & Level 2M & 6 \\
\hline & 5 & 1 & 0 & 0 & 0 & 0 & 0 & 0 & 0 & Level 1 & 2 \\
\hline & Total PEVs & 3 & 2 & 2 & 1 & 1 & 0 & 0 & 1 & & \\
\hline \multirow[t]{4}{*}{ 8-hour } & 1 & 2 & 0 & 1 & 0 & 0 & 0 & 0 & 0 & Level 1 & 8 \\
\hline & 2 & 0 & 0 & 1 & 1 & 1 & 0 & 0 & 1 & Level 2M & 7 \\
\hline & 3 & 1 & 2 & 0 & 0 & 0 & 0 & 0 & 0 & Level 1 & 8 \\
\hline & Total PEVs & 3 & 2 & 2 & 1 & 1 & 0 & 0 & 1 & & \\
\hline
\end{tabular}


Table 8. Major Emission Rates and Social Cost

\begin{tabular}{|c|c|c|c|c|}
\hline \multirow[t]{2}{*}{ Emission Type } & \multicolumn{3}{|c|}{ Emission Rates of (gram/passenger mile) } & \multirow{2}{*}{$\begin{array}{l}\text { Social } \\
\text { Cost (\$/ton) }\end{array}$} \\
\hline & Car & Diesel Bus & CNG Bus & \\
\hline VOC & 0.0453 & 0.08 & 0.436 & 1,700 \\
\hline NOx & 0.0614 & 0.927 & 3.004 & 6,700 \\
\hline PM2.5/10 & 0.0047 & 0.032 & 0.006 & 306,500 \\
\hline PM2.5/10 (TBW*) & 0.0225 & 0.06 & 0.06 & \\
\hline $\mathrm{CO}_{2}$ & 350 & 304 & 355 & 22 \\
\hline
\end{tabular}

Note: TBW stands for tire and break wear. 


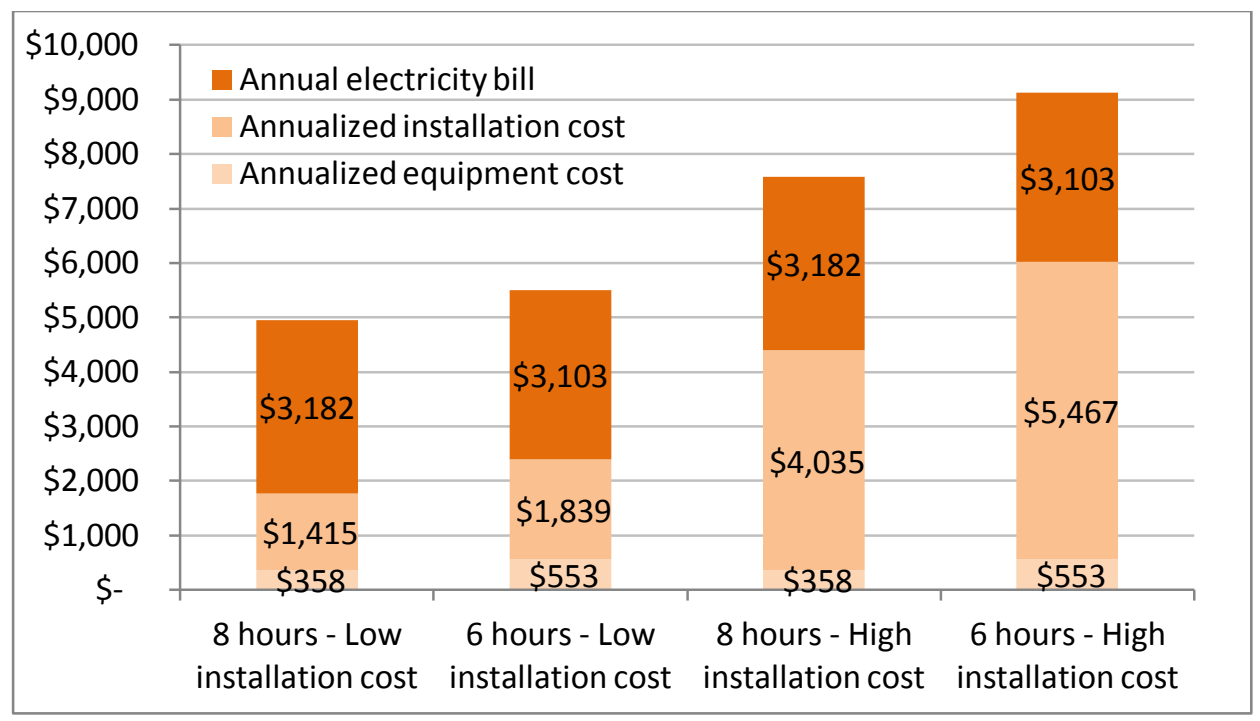

Figure 1. Breakdowns of the total annualized costs of WPC for ten PEVs. 


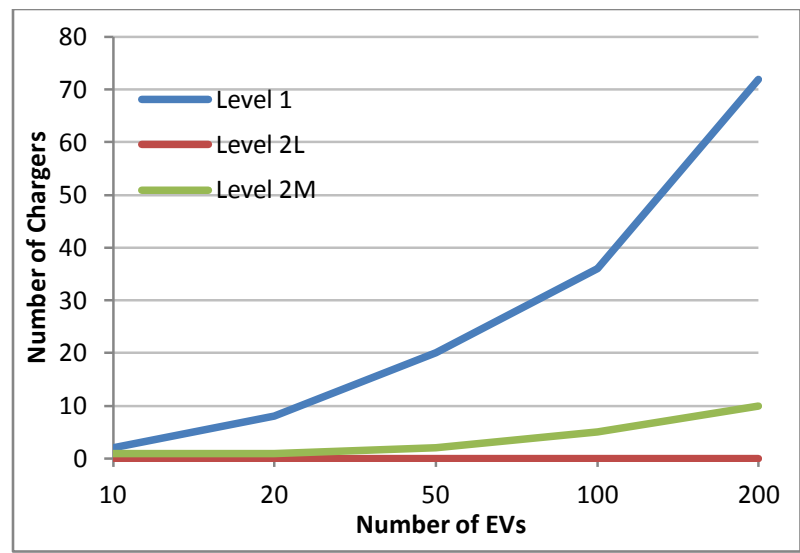

(a) 8-hour Time window with low installation cost

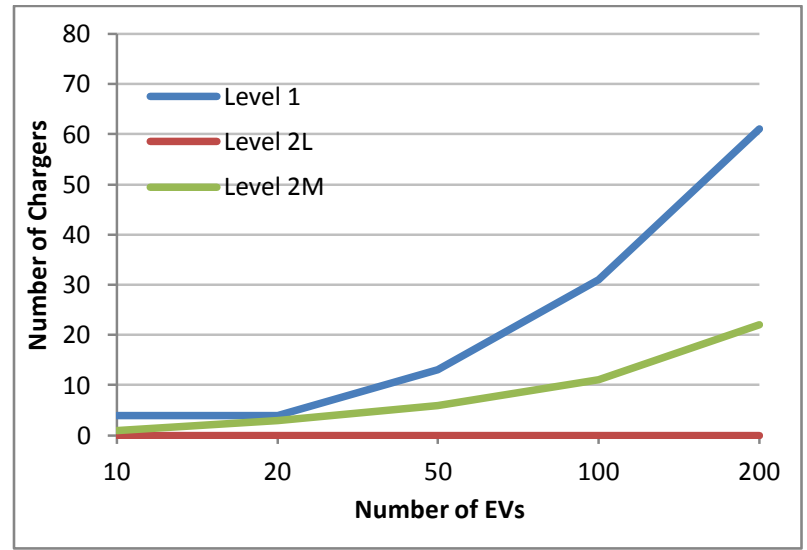

(c) 6-hour Time window with low installation cost

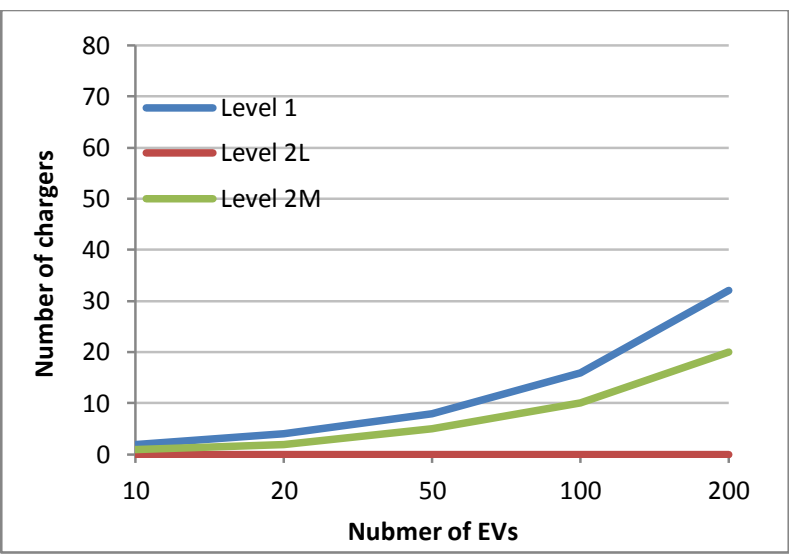

(b) 8-hour Time window with high installation cost

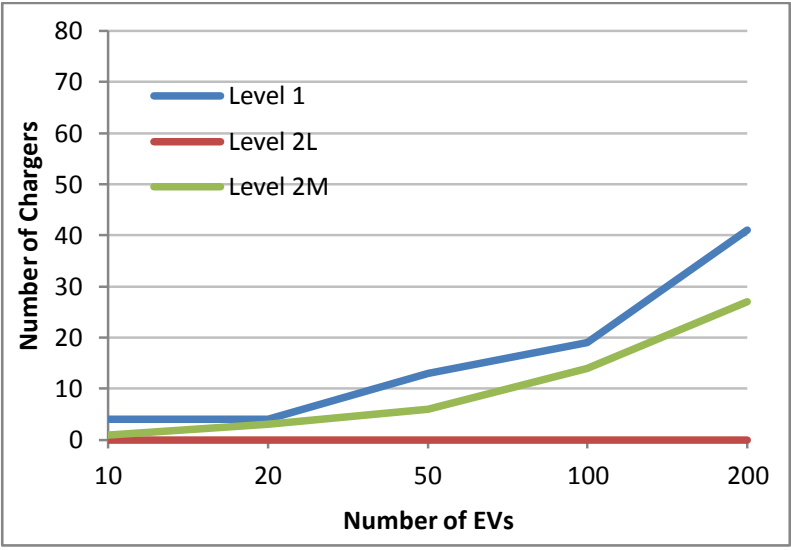

(d) 6-hour Time window with high installation cost

Figure 2. The effects of number of PEVs on the number of chargers installed 


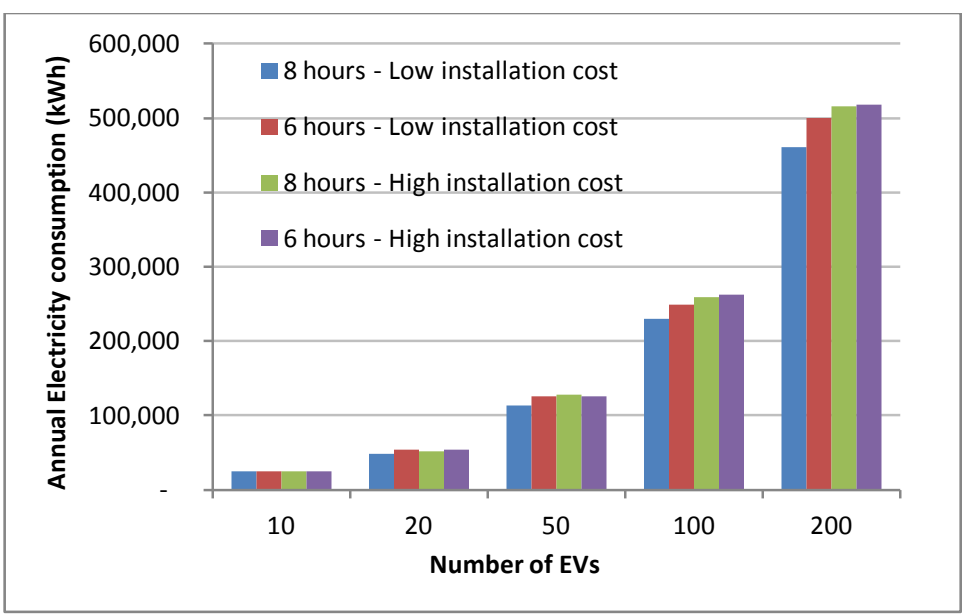

Figure 3. The effects of number of PEVs on annual electricity consumption (kWh) 


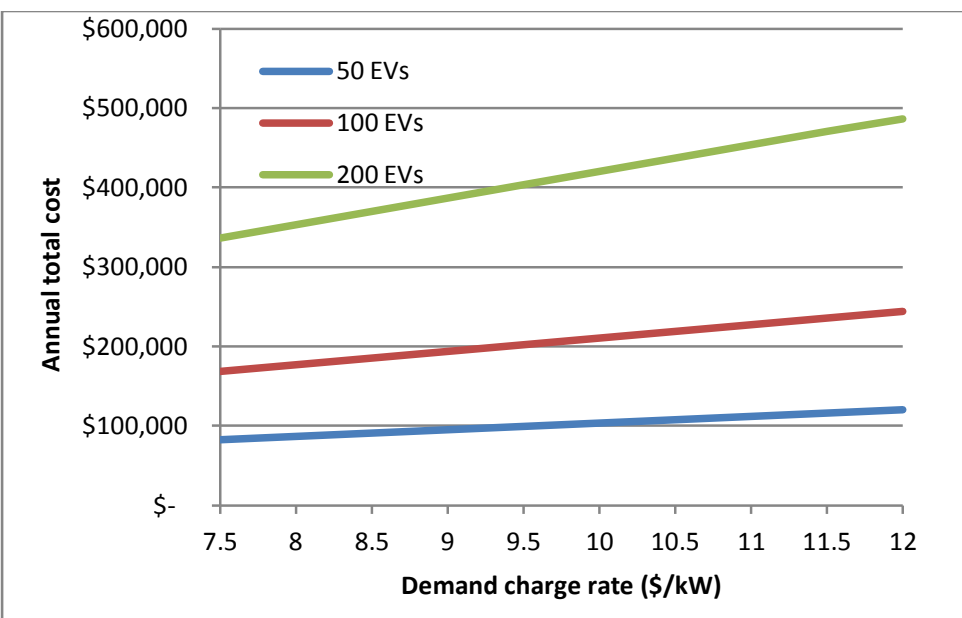

Figure 4. Total annual costs under different demand charge rates. 


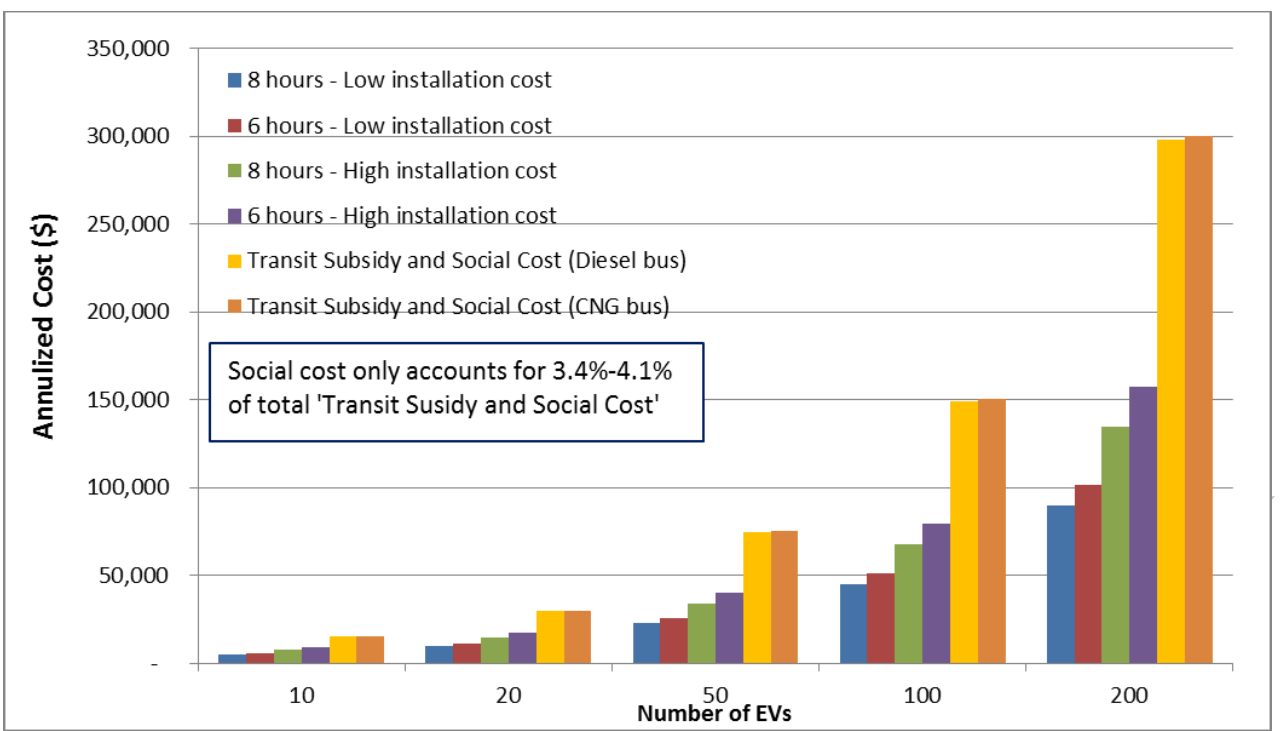

Figure 5. Annualized public transit incentive versus annualized WPC cost 